\title{
Dimensional and Geometric Deviations Induced by Milling of Annealed and Hardened AISI H13 Tool Steel
}

\author{
José Luiz S. Ribeiro ${ }^{1}$, Steve B. Diniz ${ }^{2}$, Juan Carlos Campos Rubio ${ }^{2}$, Alexandre M. Abrão, \\ ${ }^{1}$ Department of Mechatronic Engineering, Polytechnic Institute, Pontifical Catholic University of Minas Gerais, Av. Dom José Gaspar, 500, \\ Coração Eucarístico, Belo Horizonte MG, CEP: 30535-610, Brazil \\ ${ }^{2}$ Department of Mechanical Engineering, Universidade Federal de Minas Gerais, Av. Antônio Carlos, 6627 , Pampulha, Belo Horizonte \\ MG, CEP: 31.270-901, Brazil
}

\begin{abstract}
The principal goal of this paper was to investigate the influence of tool grade, cutting speed and feed rate on the dimensional (length, diameter and radius) and geometric (parallelism and angularity) deviations obtained after milling AISI H13 hot work die steel in both annealed and hardened conditions using three indexable insert grades: two coated tungsten carbides tools and one cermet tool. The results indicated that lower dimensional deviations were obtained for the external features when up-milling the softer material. Tool grade did not seem to drastically affect external dimensional errors. The dimensional deviations for the internal features were lower when up-milling the hardened steel. The cermet tool was responsible for tighter tolerances when milling the annealed steel, whereas the PVD-coated tungsten carbide tool gave the best results when machining the hardened steel. The parallelism results indicated that tighter tolerances were obtained when milling with the PVD-coated carbide tool. Finally, the angular deviation was lower when down-milling the annealed material with the cermet tool.
\end{abstract}

Keywords Milling, Tool Steel, Dimensional Deviation, Geometric Deviations

\section{Introduction}

The quality of moulds and dies subjected to milling is critical to the final cost of these products due to the influence of milling on subsequent finishing and polishing operations. Therefore, better quality rough and semi-finish milling operations result in shorter finishing and polishing cycles and lower manufacturing costs. Toh[1] presented a survey of the principal strategies used to optimise both productivity and surface quality when milling hardened die and mould materials at high speeds. Contour milling is the most common approach employed when roughing to achieve higher metal removal rates associated with less machining time. When finish milling, however, a number of factors must be taken into account, such as mould or die features, cutter geometry, the radial depth of cut and the cutter path strategy. Furthermore, the use of adaptive machining to maintain a consistent cutting load by changing cutting speed and feed rates may result in an improved surface finish, longer tool life and higher productivity.

Nevertheless, milling forces change considerably during one rotation of a cutter due to variations in chip thickness. According to Ko et al.[2], one could expect a senoidal be

* Corresponding author:

abrao@ufmg.br (Alexandre M. Abrão)

Published online at http://journal.sapub.org/materials

Copyright (C) 2012 Scientific \& Academic Publishing. All Rights Reserved haviour of the milling force components in the $\mathrm{X}$ and $\mathrm{Y}$ directions, although the dynamic complexity of the phenomenon results in a rather distinct behaviour. Altintas and Weck[3] indicated that the stability of metal cutting operations at low spindle speeds are challenging to model mainly because of the difficulty in predicting the process damping. According to Altintas and Weck, when the number of vibration waves on the machined surface during one revolution of the tooth is significant, the effective clearance angle becomes zero (or negative). Consequently, the clearance face of the tool rubs against the waves causing frictional forces against the direction of motion, which damp out chatter vibrations. Li et al.[4] report that additionally to the machining parameters, tool geometry and work material properties, the following parameters must be considered in order to accurately predict milling forces: cutting temperature variation, cutter run out, cutter and workpiece vibrations.

When cavities are machined, tool deflection changes with the cutter path, especially in corners. To minimise this effect, lower width of cut values should be employed, thus diminishing the milling force components and, consequently, tool deflection. Choy and Chan[5] proposed a strategy for cutting corners when pocket milling is implemented as a module of a commercial CAD/CAM system. The path generated by the commercial software is used as input to the developed program. An improved path is then generated to progressively remove material from the corner using single or double looping motions. Ziegert et al.[6] presented a damping de- 
vice capable of increasing the dynamic stiffness of a milling cutter by using internal flexible fingers. The authors claim that at high rotational speeds the centrifugal force presses the fingers against the inner wall of the cutter, resulting in a frictional force that reduces chatter vibrations.

Tool deflection is considered to be the most critical factor that influences both surface finish and dimensional deviations, and for this reason, a number of researchers have addressed this subject matter. $\mathrm{Xu}$ et al.[7] proposed mathematical and numerical models for predicting static and dynamic deflection of the milling cutter, and according to these authors, static deflection is more relevant than the dynamic deflection. Erzurumlu and Oktem[8] compared response surface and artificial neural network methods to predict the surface finish of a mould cavity by taking into account the following milling parameters: feed rate, cutting speed, axial and radial depths of cut and required machining tolerance. Despite the fact that the artificial neural network provided slightly lower errors $(2.05 \%$ error) than the surface response method ( $1.48 \%$ error), the latter method required a longer computational time ( 8 hours compared to a couple of seconds). Alternatively, Costes and Moreau[9] state that the roughness of milled surfaces can be predicted by measuring tool displacement using laser sensors in the $\mathrm{X}$ and $\mathrm{Y}$ directions. The maximum error (difference between predicted and measured $R_{a}$ values) was found to be $12 \%$ for flank milling and $23 \%$ for end milling $27 \mathrm{MnCr} 5$ steel.

Rao and Rao[10] studied the dimensional errors induced when milling surfaces with variable curvature; they noticed that for concave surfaces (centres of both the curvature and tool on the same side), the error tended to increase with curvature, whereas opposite results were obtained when milling convex surfaces (centre of the curvature and tool centre on opposite sides) as a consequence of respectively increasing and decreasing the force acting normally to the machined surface.

Bissey-Breton et al.[11] investigated the influence of cutter geometry (rake and helix angles) on force components when milling hardened tool steel (43 HRC) with solid carbide tools. The results indicated that the milling force components tended to decrease as the rake angle was elevated; however, it appeared that the helix angle should not exceed $45-50^{\circ}$ when cutting hardened materials to avoid an increase in the force components.

The influence of the cutter design (mechanical and thermal tool fixture), feed speed and interpolation path (linear and circular) on the dimensional deviations during high-speed milling of an aluminium alloy with coated tungsten carbide ball nose end mill was investigated by Albertí et al.[12]. Not surprisingly, the results indicated that the dimensional deviations increased with feed speed, although the findings concerning the type of fixture were not conclusive (probably because the distinct machine centres were used for each tool fixture system). Tighter tolerances were obtained when a linear interpolation path was used.

In the case of components with higher complexity and produced on transfer lines, the errors propagate from a station to the next one. Consequently, the error at the final station is affected by the errors in all previous stations[13]. According to the authors, the principal sources of errors/variations in a manufacturing system are: workpiece, machine tool, fixture, tool and holder, number of parallel stations operating simultaneously and gauge variation.

Chen and Tzeng[14] used the Taguchi method to study the influence of milling parameters on the dimensional accuracy (based on the volumetric alteration) of a component made of two different tool steels subjected to high-speed machining. Cutting speed appeared to be the most significant factor, and at higher cutting speeds, the tolerances were wider owing to the increase in tool wear and the fact that cutting instability tends to be more significant at higher speeds. Tool material was the next most significant parameter for dimensional accuracy (due to its effect on tool wear) followed by milling direction (down-milling). The lowest helix angle promoted the tightest tolerancing, and a TiAlN coating presented the best performance compared with $\mathrm{TiN}$ and $\mathrm{TiCN}$ coatings because of its superior wear resistance.

According to Dewes et al.[15], the temperature at the tool-chip interface increases with cutting speed and tool wear, although it is not dramatically affected by feed rate when milling hardened AISI H13 hot work die steel (52 HRC) with a coated carbide cutter. Similarly, Ueda et al.[16] reported that cutting temperatures increase with cutting speed and, to a lesser extent, with width of cut and feed rate. In addition, a temperature gradient of $150{ }^{\circ} \mathrm{C}$ was measured during each tooth revolution. In contrast, Chen Ming et al.[17] reported results that agreed with Salomon's model; i.e., the maximum cutting temperature was obtained at an intermediate cutting speed above which temperature tends to decrease as cutting speed is elevated. Despite the fact that the latter work was conducted using an aluminium alloy as the work material, the studies were conducted at similar spindle speed ranges of 870 to $11970 \mathrm{rpm}[15]$ and 2500 to $15000 \mathrm{rpm}[17]$. In addition to the heat caused by shearing of the work material, Schmitz et al.[18] reported that heat generated by the rotation of the main spindle and travel of the axes may affect the geometric quality of the machined part during high speed machining. Schmitz et al. compared the contribution of geometric, thermal, contouring and cutting force errors on the geometric quality of a given workpiece subjected to high-speed machining under various milling conditions; they noticed that the contribution of each error source was strongly dependent on the spindle speed error and especially the cutting force error.

\section{Experimental Procedure}

Blanks of AISI H13 hot work die steel with initial dimensions of $160 \times 160 \times 150 \mathrm{~mm}$ were used as work material. The material was supplied in two conditions: annealed with 
an average hardness of $170 \mathrm{HB}$ and hardened (quenched and tempered) to $380 \mathrm{HB}$ (41 HRC).

Three cutting tool grades supplied by Sandvik Coromant with identical geometries were tested: $\mathrm{TiCN}$ (cermet grade CT530, equivalent to ISO grade P20/H25), WC-PVD (physical vapour deposition coated tungsten carbide grade GC1025, equivalent to ISO grade P10/H15) and WC-CVD (medium temperature chemical vapour deposition coated tungsten carbide grade GC4040, equivalent to ISO grade P40). The WC-PVD tool possessed a TiCN+TiN coating, whereas the WC-CVD tool had a $\mathrm{TiN}+\mathrm{TiCN}+\mathrm{Al}_{2} \mathrm{O}_{3}$ coating. The inserts had a geometry of R300-1032E-PM and were clamped in a milling cutter code R300-25T12-10M (diameter of $25 \mathrm{~mm}$ and three teeth). Tables 1 and 2 show, respectively, the cutting conditions used when machining the work material in the annealed and hardened states.

A sample cavity containing a variety of features, such as round, square and rectangular pockets in addition to round, square and chamfered corners, was devised. Dry ramp milling tests were conducted on a machining centre with 9 $\mathrm{kW}$ of power and a $7500 \mathrm{rpm}$ maximum rotational speed. One cavity was machined under each cutting condition resulting in 10 test runs.

In the case of the tool steel in the annealed condition (Table 1), cutting tool grades TiCN (cermet) and WC-CVD (medium temperature CVD coated tungsten carbide) were selected because these grades provided superior performance in previous tests involving tool life measurements. Furthermore, the influence of feed rate on tool life was considerably higher than that of cutting speed; therefore, the cutting speed parameter and the depth and width of cut remained constant during the tests with the annealed material. Consequently, only the influences of tool material, feed rate and milling direction were investigated in these tests.

With regard to the machining conditions applied to the hardened tool steel (Table 2), tool grades WC-PVD (tungsten carbide coated by physical vapour deposition) and TiCN (cermet) were used for the same reason given above (i.e., they provided longer tool lives in previous tests). However, cutting speed had a more significant influence on tool life than feed rate, which, together with depth and width of cut, remained constant. Thus, the influence of tool material, cutting speed and milling strategy was assessed when cutting the hardened samples.

Figure 1 shows the top view of the cavity and indicates the dimensions and deviations that were measured after machining. Table 3 presents the dimensional and geometric features that were evaluated. These deviations were measured with a Tesa Micro - Hite 3D coordinated measuring machine (resolution of $1 \mu \mathrm{m}$ and accuracy of $3 \mu \mathrm{m}$ ) using a ruby probe with $2 \mathrm{~mm}$ diameter.

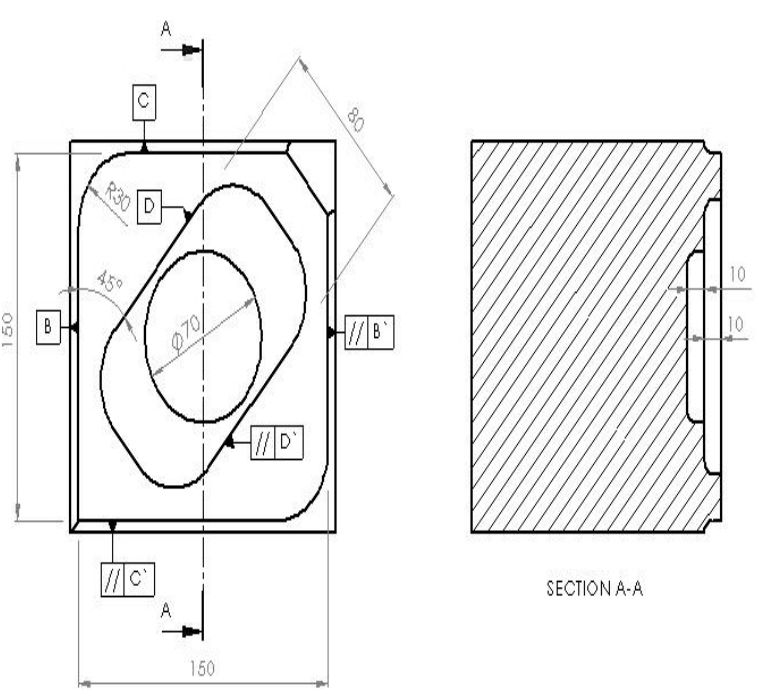

Figure 1. Top view with selected dimensions and deviations.

Table 1. Cutting conditions employed when milling annealed tool steel (170 HB).

\begin{tabular}{|c|c|c|c|c|c|c|}
\hline Test run & Tool grade & $\begin{array}{c}\text { Cutting speed } \\
v_{c}(\mathrm{~m} / \mathrm{min})\end{array}$ & $\begin{array}{c}\text { Feed rate } \\
f_{z}(\mathrm{~mm} / \mathrm{rev})\end{array}$ & $\begin{array}{c}\text { Depth of cut } \\
a_{p}(\mathrm{~mm})\end{array}$ & $\begin{array}{c}\text { Width of cut } \\
a_{e}(\mathrm{~mm})\end{array}$ & Direction \\
\hline 1 & TiCN & 370 & 0.25 & 0.5 & 12.5 & Up milling \\
\hline 2 & TiCN & 370 & 0.15 & 0.5 & 12.5 & Up milling \\
\hline 3 & WC-CVD & 370 & 0.25 & 0.5 & 12.5 & Up milling \\
\hline 4 & WC-CVD & 370 & 0.15 & 0.5 & 12.5 & Up milling \\
\hline 5 & WC-CVD & 370 & 0.15 & 0.5 & 12.5 & Down milling \\
\hline
\end{tabular}

Table 2. Cutting conditions employed when milling hardened tool steel $(380 \mathrm{HB})$.

\begin{tabular}{|c|c|c|c|c|c|c|}
\hline Test run & Tool grade & $\begin{array}{c}\text { Cutting speed } \\
v_{c}(\mathrm{~m} / \mathrm{min})\end{array}$ & $\begin{array}{c}\text { Feed rate } \\
f_{z}(\mathrm{~mm} / \mathrm{rev})\end{array}$ & $\begin{array}{c}\text { Depth of cut } \\
a_{p}(\mathrm{~mm})\end{array}$ & $\begin{array}{c}\text { Width of cut } \\
a_{e}(\mathrm{~mm})\end{array}$ & Direction \\
\hline 6 & WC-PVD & 170 & 0.10 & 0.5 & 12.5 & Up milling \\
\hline 7 & WC-PVD & 120 & 0.10 & 0.5 & 12.5 & Up milling \\
\hline 8 & TiCN & 170 & 0.10 & 0.5 & 12.5 & Up milling \\
\hline 9 & TiCN & 120 & 0.10 & 0.5 & 12.5 & Up milling \\
\hline 10 & TiCN & 120 & 0.10 & 0.5 & 12.5 & Down milling \\
\hline
\end{tabular}


Table 3. Dimensional and geometric features.

\begin{tabular}{|c|c|c|}
\hline \multicolumn{2}{|c|}{ Dimensional deviations } & Geometric deviations \\
\hline Feature & $\begin{array}{c}\text { Nominal } \\
\text { value (mm) }\end{array}$ & Feature \\
\hline Length BB' & 150 & Parallelism BB (//BB') \\
Length CC' & 150 & Parallelism CC (//CC') \\
Length DD' & 80 & Parallelism DD (//DD') \\
Circular pocket Ø70 & 70 & Angularity DB (DB45) \\
External radius R30 & 30 & \\
\hline
\end{tabular}

Finally, Figure 2 presents an actual machined sample that is being measured in the coordinate measuring machine. Attention must be paid to the fact that lengths $\mathrm{BB}^{\prime}$ and $\mathrm{CC}^{\prime}$ and radius $\mathrm{R} 30$ are external measures, whereas length DD' and the circular pocket $\varnothing 70$ are internal measures; therefore, the results are presented and discussed according to these two groups, followed by angularity DB, which involves internal and external tool paths.

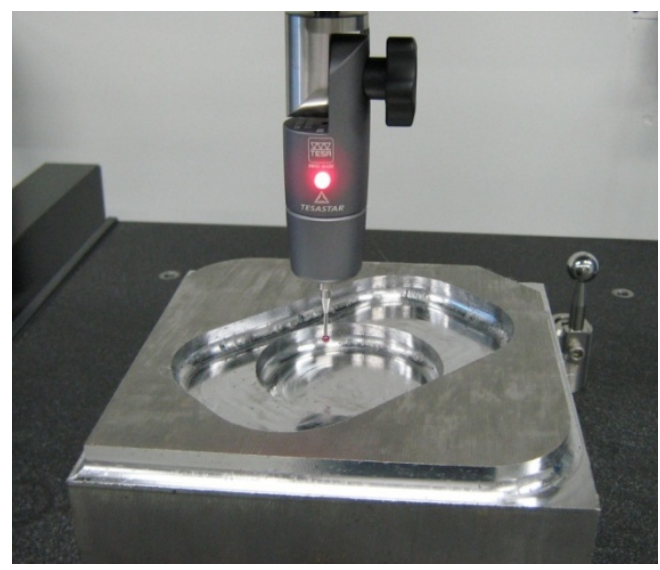

Figure 2. Machined cavity undergoing assessment.

\section{Results and Discussion}

The results are presented as plots of the main effects for each feature that was assessed. For the sake of conciseness, interaction plots are not presented in this work, although their results are discussed when necessary. Figures 3 to 5 show the main effects plots for the dimensional deviations in lengths BB' and CC' and external radius R30, respectively. In general, the same behaviours were observed in these three graphs, which show that the deviations were in the range of hundredths of millimetres. The deviations increased slightly with the hardness of the work material due to higher milling forces and plastic strain. Although the influence of tool grade seemed to be negligible, the interaction plots indicated that the cermet tool ( $\mathrm{TiCN}$ ) outperformed the CVD coated carbide tool (WC-CVD) when milling the annealed material and was outperformed by the PVD coated carbide tool (WC-PVD) when cutting the hardened work material. Such behaviour can be explained by the superior hardness of both the substrate and coating of the WC-PVD tool (1650 HV and $3000 \mathrm{HV}$, respectively, compared to a substrate hardness of $1490 \mathrm{HV}$ for the uncoated cermet and substrate and coating hardness values of $1250 \mathrm{HV}$ and $2500 \mathrm{HV}$, respectively, for the WC-CVD tool), according to Diniz et al.[19]. The effect of an increasing cutting speed must be analysed by considering the work material hardness because variable cutting test speeds of 120 and $170 \mathrm{~m} / \mathrm{min}$ were used for the hardened material (380 HV) only, whereas trials using annealed specimens $(170 \mathrm{HV})$ were conducted at a constant cutting speed of $v_{c}=370 \mathrm{~m} / \mathrm{min}$. However, it was observed that an increase in cutting speed promoted a reduction in the dimensional error measured on the hardened steel, which was probably due to the softening of the work material caused by the increase in the cutting zone temperature. Moreover, similar error values were obtained when milling the tool steel in the hardened state using a cutting speed of $170 \mathrm{~m} / \mathrm{min}$ compared with the material in the annealed condition at $v_{c}=370 \mathrm{~m} / \mathrm{min}$. The findings related to the influence of feed rate must be discussed in a similar manner: feed rate values of 0.15 and $0.25 \mathrm{~mm} / \mathrm{rev} /$ tooth were used for the annealed material, and a constant $f_{z}=0.1 \mathrm{~mm} / \mathrm{rev} /$ tooth was employed when cutting the hardened specimens.

However, an unexpected behaviour was recorded: the dimensional deviation was reduced as the feed rate was increased. One possible explanation may reside in the work hardening of the work material surface layers caused by shearing. In this case, a feed rate increase would result in the cutting of a portion of material ahead of the strained region, and consequently, lower milling forces and dimensional deviations would be obtained.

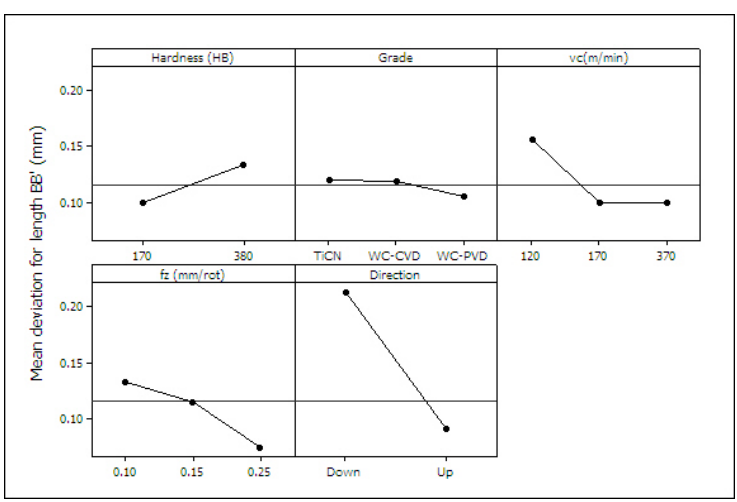

Figure 3. Effect of cutting conditions on the dimensional deviation for length BB'.

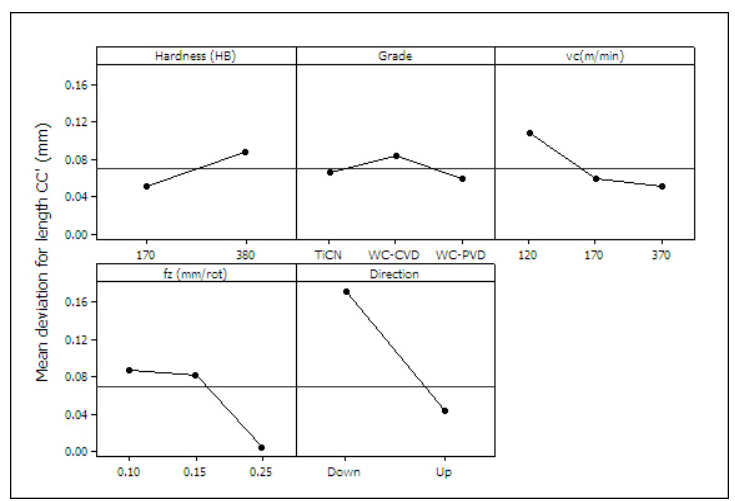

Figure 4. Effect of cutting conditions on the dimensional deviation for length $\mathrm{CC}^{\prime}$ '. 


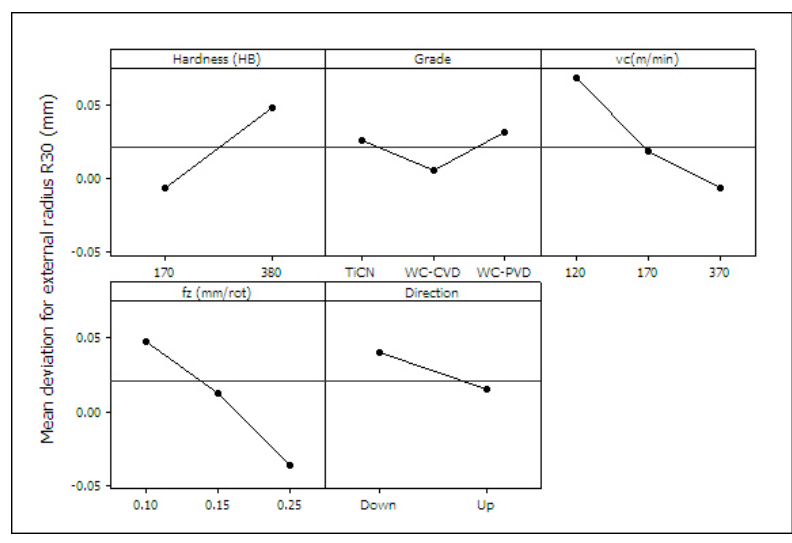

Figure 5. Effect of cutting conditions on the external radius deviation (R30).

Finally, the plots showing the influence of the milling direction indicate that lower dimensional deviations were generated when up-milling in comparison to down-milling, which can be explained by the greater extent of plastic deformation associated with the maximum chip thickness at the beginning of the cut when down-milling, thus promoting vibration. According to Altintas[20], when two or more teeth are cutting simultaneously, the teeth aligned in the Y direction tend to deflect either toward the workpiece in up-milling (cutting extra material from the surface) or away from the in down-milling (leaving material on the surface). Furthermore, no interactions were observed between milling direction and other factors.

Figures 6 and 7 show the results for length DD' and a circular pocket with an internal diameter of $70 \mathrm{~mm}(\varnothing 70)$, respectively. In the former case, a distinct scenario was observed when the workpiece was required to simultaneously travel in both the $\mathrm{X}$ and $\mathrm{Y}$ directions to produce a tilted cavity, as seen in Figure 6, in which the resulting dimensional error was a combination of errors associated with the $\mathrm{X}$ and $\mathrm{Y}$ axes. The findings for length DD' show that the deviations were in the range of tenths of a millimetre and that negative values were obtained; these results indicate that the measured values were smaller than the nominal value due to tool deflection, and therefore plots of the main effects should be analysed from this perspective.

This means that lower deviations for length DD' were obtained when milling the material in the hardened condition using the up-milling direction. The unexpected effect of workpiece hardness on the dimensional error can be explained by the fact that a lower feed rate was employed in this case $\left(f_{z}=0.10 \mathrm{~mm} / \mathrm{rev}\right)$ compared to the machining of the annealed tool steel $\left(f_{z}=0.15\right.$ and $\left.0.20 \mathrm{~mm} / \mathrm{rev}\right)$. Consequently, lower forces and tighter tolerances were produced. Tool grade TiCN provided the best results followed closely by grade WC-PVD, whereas grade WC-CVD gave the worst results. An intermediate cutting speed value of $v_{c}=170 \mathrm{~m} / \mathrm{min}$ was responsible for the lower error, although the best results were obtained using extreme feed rate values. Similar to length DD', tool deflection led to negative deviations when milling the circular pocket $\varnothing 70$ (Figure 7), and the best re- sults were produced when the hardened material was milled in the up-milling direction using the slowest feed rate. Use of the slowest feed rate when milling the circular pocket resulted in lower deviations for the hardened work material compared with to annealed condition. Moreover, the cermet tool gave lower errors (when cutting the annealed material), whereas the PVD coated tungsten carbide provided lower deviations when machining the hardened steel. An increase in cutting speed from 120 to $170 \mathrm{~m} / \mathrm{min}$ resulted in lower dimensional deviations when cutting the hardened steel, probably due to a reduction in the milling force caused by softening of the work material.

Figures 8 and 9 present the results for parallel lengths BB' and $\mathrm{CC}^{\prime}$, respectively. By comparing both graphs, one can notice that considerably wider parallelism tolerances (//CC') were obtained when milling in the $\mathrm{X}$ direction.

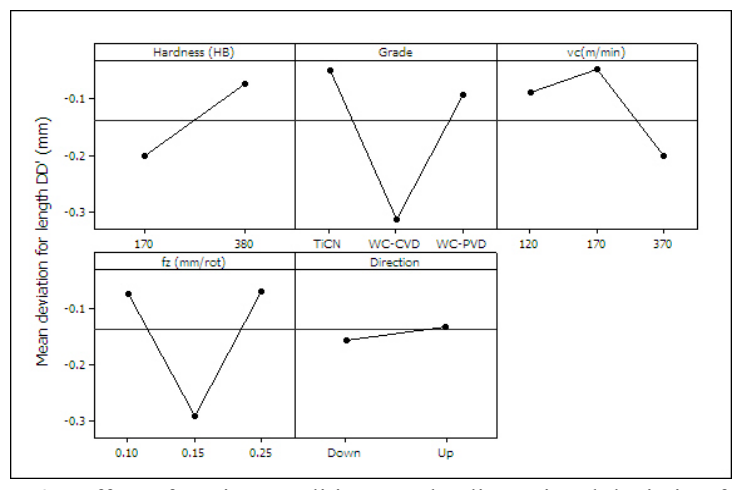

Figure 6. Effect of cutting conditions on the dimensional deviation for length DD'.

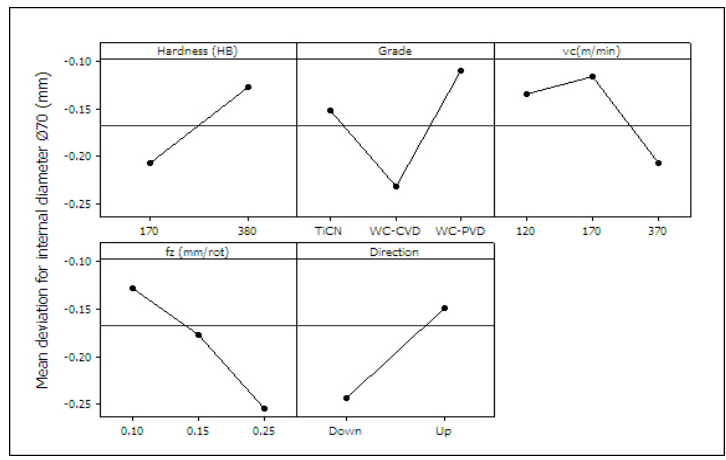

Figure 7. Effect of cutting conditions on the diameter deviation (Ø70).

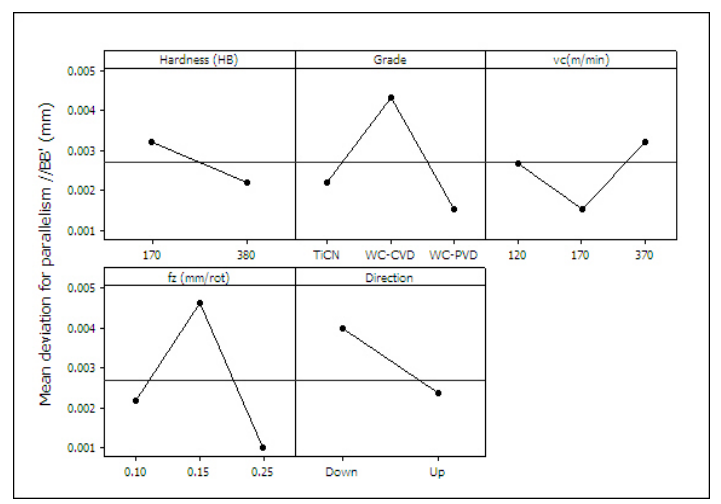

Figure 8. Effect of the cutting conditions on //BB'. 


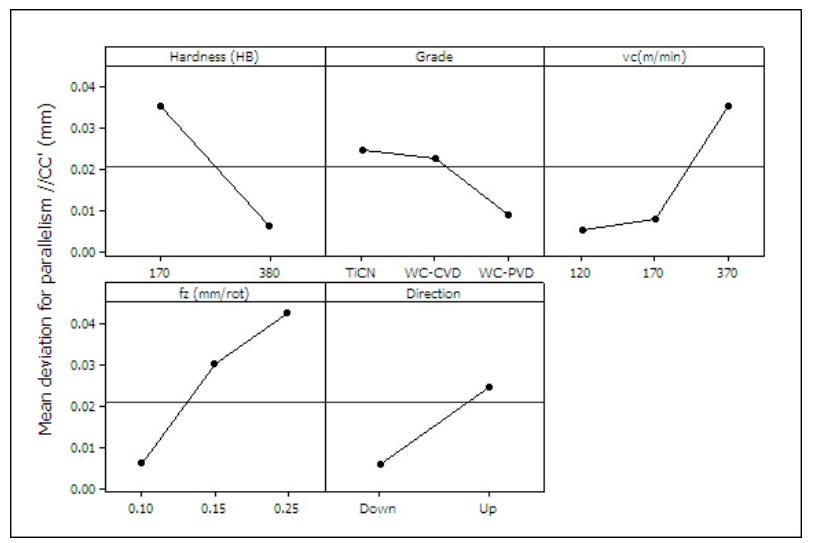

Figure 9. Effect of the cutting conditions on //CC'.

This result can be explained by the fact that the work table responsible for the $\mathrm{X}$ direction was mounted on the top of the work table associated with travel in the $\mathrm{Y}$ direction. As a result, //CC' incorporated the errors from two sets of ball screws and guideways. Furthermore, both parallelism deviations decreased as the workpiece hardness increased. Such behaviour could be explained by the fact that lowest feed rate was employed when milling the hardest material.

With regard to the influence of tool grade on parallelism, the WC-PVD insert presented superior performance when milling hardened H13 steel; however, when machining steel in the annealed state, the cermet tool outperformed the WC-CVD for //BB', whereas both grades provided similar results for //CC'. Contrasting results were found when the cutting speed was increased from 120 to $170 \mathrm{~m} / \mathrm{min}$ (for material hardened to $380 \mathrm{HV}$ ) and the feed rate was increased from 0.15 to $0.25 \mathrm{~mm} / \operatorname{rot}(170 \mathrm{HV})$, thus indicating that the machine tool components had a significant influence.

In general, results for the parallelism deviation of DD'(Figure 10) followed the same trend and range observed for //CC'; i.e., higher deviations were recorded owing to the combination of the travel in two directions.

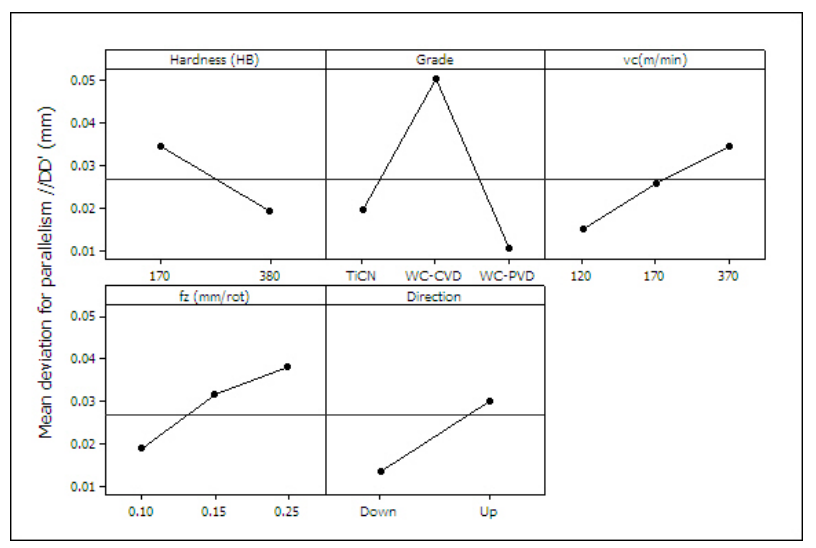

Figure 10. Effect of the cutting conditions on //DD'.

The influence of machining parameters on the angular deviation of DB45 is given in Figure 11 in terms of the difference from the nominal value $\left(45^{\circ}\right)$ measured in seconds. The findings indicate that work material hardness and cutting speed did not have a dramatic influence, although deviations tended to increase with hardness and decrease with higher cutting speed. The cermet tool ( $\mathrm{TiCN})$ was superior when machining the annealed steel, whereas the PVD coated carbide tool presented the best performance for the hardened steel. Unexpectedly, lower deviations were obtained as the feed rate was increased and when down-milling.

Finally, Figures 12 and 13 present the mean values and corresponding intervals for dimensional deviations and parallelism, respectively, using a confidence level of $95 \%$. Figure 12 shows that with the exception of length DD', for which the variability was $0.259 \mathrm{~mm}$, similar variabilities were obtained for the remaining parameters (the maximum variability was $0.106 \mathrm{~mm}$ for internal diameter $\emptyset 70$ ). Furthermore, positive mean values were obtained after machining the external features (lengths BB' and $\mathrm{CC}^{\prime}$ ), and negative mean values were found for the internal features (length DD' and internal diameter 670 ). A negative mean was obtained for the external radius R30, despite the fact that this was an external feature. This result can be explained by the fact that length DD' was generated by moving the workpiece in both the $\mathrm{X}$ and $\mathrm{Y}$ directions simultaneously, and the effect was similar to that observed for internal diameter $\emptyset 70$ and radius $\mathrm{R} 30$.

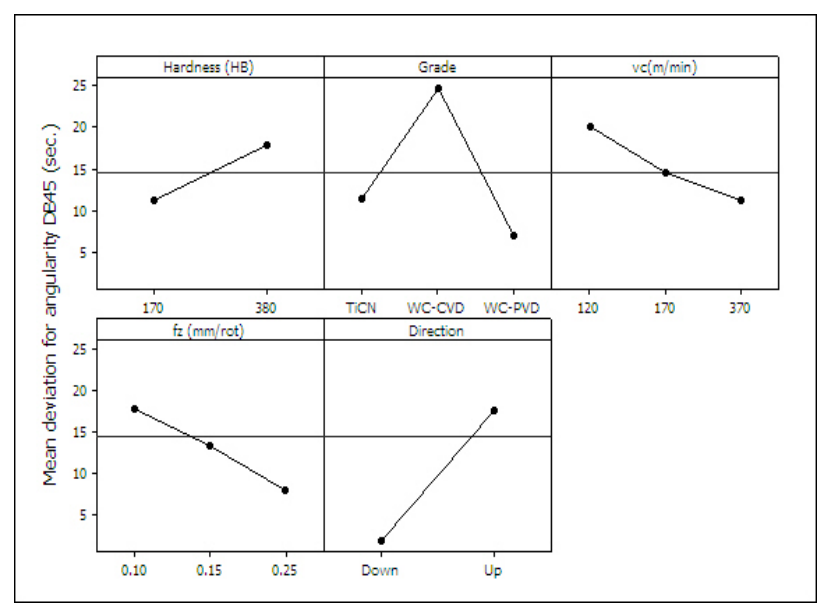

Figure 11. Effect of cutting conditions on the angularity of DB45.

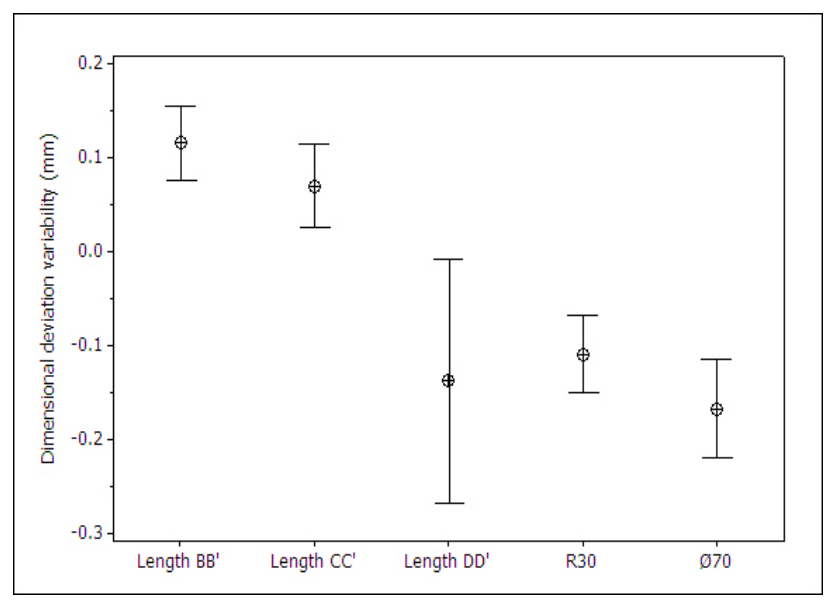

Figure 12. Dimensional deviation variability. 


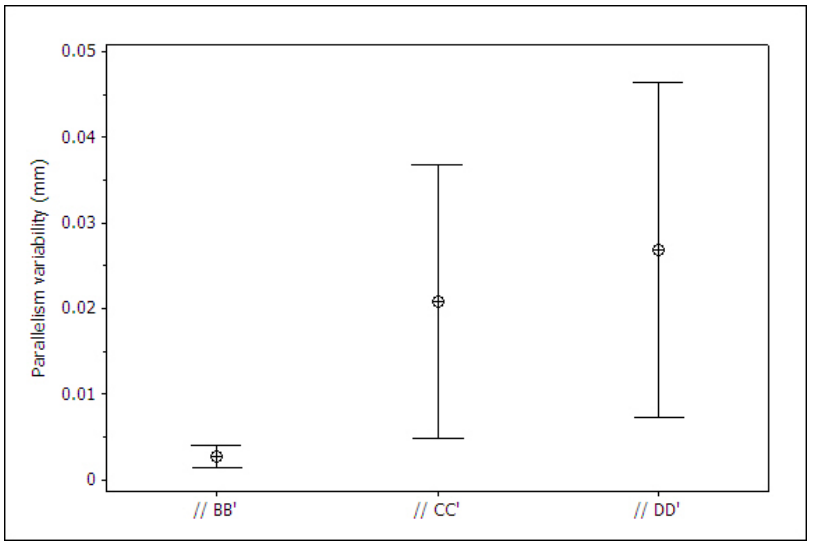

Figure 13. Parallelism variability.

Figure 13 presents interval plots for the parallelism deviations, which show that a considerably smaller variability was obtained (the interval for the parallelism of BB' was $3 \mu \mathrm{m}$; i.e., it was equivalent to the precision of the coordinate measuring machine) compared to the dimensional deviations (maximum of $0.039 \mathrm{~mm}$ for //DD'). In addition, the combination of movements in the $\mathrm{X}$ and $\mathrm{Y}$ directions resulted in a wider scatter for //DD' due to the propagation of errors from the components of two travel systems. The interval plot for the angularity of DB45 was not included in Figure 13 because this was a distinct feature that did not allow for a straightforward comparison with the parallelism results. In this case, a mean value of $14.5 \mathrm{sec}$. and a variability of $51 \mathrm{sec}$. were obtained.

\section{Conclusions}

After milling cavities in annealed (170 HV) and hardened (380 HV) AISI H13 hot work die steel using CVD and PVD coated carbide and cermet inserts under various machining parameters, the following conclusions were drawn:

- The dimensional deviations obtained after milling external features (lengths BB' and CC' and external radius R30) were affected by the machining parameters in a similar fashion; i.e., tighter tolerances were produced when up-milling the softer material. Tool grade did not seem to drastically affect the external dimensional errors. In general, lower deviations were obtained when milling the annealed material at a feed rate of $f_{z}=0.25 \mathrm{~mm} / \mathrm{rot}$ and the hardened material at a cutting speed of $v_{c}=170 \mathrm{~m} / \mathrm{min}$.

- The dimensional deviations measured after the machining of internal features (length DD' and internal diameter Ø70) showed a similar behaviour with regard to nearly all evaluated parameters: a lower error was obtained after up-milling of the hardened steel, and the cermet tool was responsible for tighter tolerances when milling the annealed steel at a feed rate of $f_{z}=0.25 \mathrm{~mm} /$ rot. The PVD coated tungsten carbide gave the best results for the hardened steel at a cutting speed of $v_{c}=170 \mathrm{~m} / \mathrm{min}$.

- The parallelism results did not present the same level of consistency: tighter tolerances were obtained when milling the hardened tool steel in the Y direction with the PVD coated carbide tool.

- Finally, the angular deviation was lower when down-milling the annealed material with the cermet tool at a feed rate of $f_{z}=0.25 \mathrm{~mm} / \mathrm{rot}$ and when cutting the hardened workpiece at a cutting speed of $v_{c}=170 \mathrm{~m} / \mathrm{min}$.

\section{ACKNOWLEDGEMENTS}

The authors would like to thank Prof. Anderson Paulo de Paiva (Institute of Production Engineering, University of Itajubá, Brazil) for helpful discussions concerning the statistical analysis of the results and the following Brazilian research agencies for supporting this project: CNPq, CAPES and FAPEMIG. Additional thanks go to Sandvik Coromant, Traterminas Ltd. and Villares Metals S/A for the provision of consumables.

\section{REFERENCES}

[1] Toh, C.K., 2005, Design, evaluation and optimisation of cutter path strategies when high speed machining hardened mould and die materials, Mater. Des., 26, 517-533

[2] Ko, J.H., Yun, W.S., Cho, D.W. and Ehman, K.F., 2002, Development of a virtual machining system, part 1: approximation of the size effect for cutting force prediction, Int. J. Mach. Tools Manufact., 42, 1595-1605

[3] Altintas, Y. and Weck, M., 2004, Chatter stability of metal cutting and grinding, CIRP Annals - Manufact. Technol., 53, 619-642

[4] Li, X.P., Zheng, H.Q., Wong, Y.S. and Nee, A.Y.C., 2000, An approach to theoretical modeling and simulation of face milling forces, J. Manufact. Process., 2, 224-240

[5] Choy, H.S. and Chan, K.W., 2002, Enhanced strategy for milling corners, Proc. IMechE Part B: J. Eng. Manufact., $1135-1154$

[6] Ziegert, J.C., Stanislaus, C., Schmitz, T.L. and Sterling, R., 2006, Enhanced damping in long slender end mills, J. Manufact. Process., 8, 39-46

[7] Xu, A.P., Qu, Y.X. Zhang, D.W. and Huang, T., 2003, Simulation and experimental investigation of the end milling process considering the cutter flexibility, Int. J. Mach. Tools Manufact., 43, 283-292

[8] Erzurumlu, T. and Oktem, H., 2007, Comparison of response surface model with neural network in determining the surface quality of moulded parts, Mater. Des., 28, 459-465

[9] Costes, J.P. and Moreau, V., Surface roughness prediction in milling based on tool displacements, J. Manufact. Process. (2011), doi:10.1016/j.jmapro.2011.02.003

[10] Rao, V.S. and Rao, P.V.M., 2006, Effect of workpiece curvature on cutting forces and surface error in peripheral milling, Proc. IMechE Part B: J. Eng. Manufact., 220, 1399-1407

[11] Bissey-Breton, S., Poulachon, G. and Lapujoulade, F., 2006, 
Integration of tool geometry in prediction of cutting forces during milling of hard materials, Proc. IMechE Part B: J. Eng. Manufact., 220, 579-587

[12] Albertí, M., Ciurana, J. and Rodriguez, C.A., 2007, Experimental analysis of dimensional error vs. cycle time in high-speed milling of aluminium alloy, Int. J. Mach. Tools Manufact., 47, 236-246

[13] Agapiou, J.S., Steinhilper, E., Gu, F. and Bandyopadhyay, P., 2003, Modeling machining errors on a transfer line to predict quality, J. Manufact. Process., 5, 1-12

[14] Chen, F.C. and Tzeng, Y.F., 2004, Optimization of the volumetric accuracy of high-speed computer numerical control milling with dynamic quality characteristics, Proc. IMechE Part B: J. Eng. Manufact., 218, 1741-1754

[15] Dewes, R.C., Ng, E., Chua, K.S., Newton, P.G. and Aspinwall, D.K. Temperature measurement when high speed machining hardened mould/die steel, J. Mater. Process. Technol. 92-93 (1999) 293-401
[16] Ueda, T., Hosokawa, A., Oda, K. and Yamada, K., 2001, Temperature on flank face of cutting tool in high speed milling, CIRP Annals - Manufact. Technol., 50, 37-40

[17] Chen Ming, Sun Fanghong, Wang Haili, Yuan Renwei, Qu Zhenghong and Zhang Shuqiao, 2003, Experimental research on the dynamic characteristics of the cutting temperature in the process of high-speed milling, J. Mater. Process. Technol., $138,468-471$

[18] Schmitz, T.L., Ziegert, J.C., Canning, J.S. and Zapata, R., 2008, Case study: A comparison of error sources in high-speed milling, Prec. Eng., 32, 126-133

[19] Diniz, A.E., Ferreira, J.R. and Silveira, J.F., 2004, Toroidal millling of hardened SAE H13 steel, J. Braz. Soc. Mech. Sci. Eng., 26, 17-21

[20] Altintas, Y., 2000, Manufacturing automation: metal cutting mechanics, machine tool vibrations, and CNC design, first ed., Cambridge University Press, New York 